\title{
Clinical Outcome and Prognosis of Patients Admitted to the Surgical ICU after Abdomen Surgery
}

\author{
Yun Su Sim, M.D., Jin Hwa Lee, M.D. ${ }^{1}$, Jung Hyun Chang, M.D. ${ }^{1}$, and Yon Ju Ryu, M.D. ${ }^{1}$ \\ Division of Pulmonary, Allergy and Critical Care Medicine, Department of Internal Medicine, Hallym University Kangnam Sacred Heart Hospital, and 'Division of Pulmonary and Critical \\ Care Medicine, Department of Internal Medicine, Ewha Medical Center and Ewha Medical Research Institute, Ewha Womans University School of Medicine, Seoul, Korea
}

Background: Postoperative admission to the surgical intensive care unit (S-ICU) is commonly planned to prevent and treat complications, unnecessary admission to the S-ICU increases medical costs and length of hospital stay. This study aimed evaluated outcome and the predictive factors for mortality in patients admitted to the S-ICU after abdominal surgery.

Methods: The 168 patients admitted to the S-ICU immediately after abdominal surgery were reviewed retrospectively from January to December 2011.

Results: The mortality rate of patients admitted to the S-ICU after abdominal surgery was $8.9 \%$ (15 of 168). Two preoperative factors (body mass index [BMI] $<18.5 \mathrm{~kg} / \mathrm{m}^{2}[\mathrm{p}<0.001]$ and serum albumin $<3.0 \mathrm{~g} / \mathrm{dL}[\mathrm{p}=0.018]$ ), two operative factors (the need for transfusion [ $p=0.008$ ] or vasopressors [ $p=0.013$ ] during surgery), and three postoperative variables (mechanical ventilation immediately following surgery [ $<0.001$, sequential organ failure assessment $[p=0.001]$ and SAPS II [ $=0.001]$ score) were associated with mortality in univariate analysis. After adjusting for age, gender, and SAPS II by a Cox regression, which revealed that BMI $<18.5 \mathrm{~kg} / \mathrm{m}^{2}(\mathrm{p}<$ 0.001 , hazard ratio $[H R]$ 9.690, 95\% confidence interval [Cl] 2.990-25.258) and the use of mechanical ventilation on admission to S-ICU (p $<0.001, \mathrm{HR} 34.671,95 \% \mathrm{Cl} 6.440-186.649)$ were independent prognostic factors.

Conclusions: In patients in S-ICU after abdominal surgery, low BMI and postsurgical mechanical ventilation should be considered important predictors of mortality.

Key Words: body mass index; intensive care units; postoperative complications; surgery.

\section{Introduction}

Postoperative admission to the surgical intensive care unit (S-ICU) is commonly planned to prevent and treat complications, as postoperative complications are an important cause of surgery-related mortality and morbidity.[1] However, treatment of patients in the intensive care unit (ICU) increases medical costs and length of hospital stay, and many patients suffer from unfamiliar circumstances and excessive procedures in the ICU.[1-4] Thus, evaluation of predictive factors related to poor out-

Received on March 12, 2014 Revised on October 8, 2014

Accepted on November 10, 2014

Correspondence to: Yon Ju Ryu, Division of Pulmonary and Critical Care Medicine, Department of Medicine, Ewha Medical Center and Ewha Medical Research Institute, Ewha Womans University, School of Medicine, Mokdong Hospital, 1071, Anyangcheon-ro, Yangcheon-gu, Seoul 158-710, Korea Tel: +82-2-2650-2840, Fax: +82-2-2650-2559

E-mail: medyon@ewha.ac.kr

*No potential conflict of interest relevant to this article was reported. comes is required to ensure facilitate decision making regarding patient admission to the ICU after surgery.

Abdominal surgery causes various postoperative complications due to the presence of the gastrointestinal bacterial flora and long postoperative fasting periods.[5-9] In particular, pulmonary complications occur frequently in abdominal and thoracic surgery because of the decline in lung volume and respiratory depression due to pain during respiration and the 
effects of anesthesia.[5-9] Therefore many patients are admitted to the S-ICU after abdominal surgery, there are few studies for the outcome of patients in the S-ICU after abdominal surgery.

This study aimed to evaluated the clinical outcomes of patients in the ICU after abdominal surgery, and identify the prognostic factors contributing to mortality in these patients.

\section{Materials and Methods}

\section{1) Setting and subjects}

The study was performed in an 857-bed referral hospital in Seoul, Korea. It contains five ICUs including medical ICU (15 beds), surgical ICU (14 beds), cardiac ICU (seven beds), neurological ICU (18 beds), and neonatal ICU (12 beds).

We selected patients $\geq 18$ years of age who were admitted to the ICU after abdominal surgery from January 2011 through December 2011. We excluded patients who underwent non-invasive procedures, such as abdominal wound dressing in the operating room and those who underwent urological, abdominal vascular and gynecological procedures. Malignancy was confirmed by surgical pathologic findings. Finally, 168 patients were evaluated retrospectively. The retrospective study was approved by the Institutional Review Board of Ewha Medical Center (IRB Number: ECT 12-10-02).

\section{2) Variables}

The analyzed preoperative variables included patient demographics, comorbidities, laboratory findings, smoking history. A low body mass index (BMI) was defined as $\leq 18.5$ $\mathrm{kg} / \mathrm{m}^{2}$ according to the World Health Organization criteria for BMI.[10] All patients were classified according to the American Society of Anesthesiologists (ASA) classification. Operative factors were evaluated by surgical site, duration of surgery, treatment during operation, whether the surgery was related to cancer, and the emergency state. We also analyzed the use of mechanical ventilation. Mechanical ventilation was started on admission to the ICU. The duration of ICU stay, Simplified Acute Physiology Score (SAPS) II, sequential organ failure assessment (SOFA), and laboratory findings were the postoperative variables.

\section{3) Statistics}

Statistical analysis was performed using the SPSS-PC software for Windows version 17.0 (SPSS Inc, Chicago, IL, USA). Descriptive data are expressed as medians with range and frequencies, which are expressed as numbers (\%). Median value was used for the groups of SAPS II and SOFA scores. To identify the prognostic factors contributing to mortality, Cox proportional hazards models were used. The factors that were significantly associated with the mortality at a $p$ value of $<0.05$ were included in the multivariate model. Age, sex, and SAPS II were also adjusted in the multivariate model. Hazard ratios (HRs) with 95\% confidence intervals (CIs) were used to report the results. Cumulative survival probabilities were estimated by Kaplan Meier methods, and the log-rank test was applied to compare survival curves among patients according to BMI and use of mechanical ventilation.

\section{Results}

\section{1) Clinical characteristics and outcome of ICU patients after abdominal surgery}

The characteristics of the 168 patients are summarized in Table 1. The median age was 72 years (range, 18-90 years); 94 patients $(56 \%)$ were male. The median BMI was $23.0 \mathrm{~kg} /$ $\mathrm{m}^{2}$ (range, $15.6-32.9 \mathrm{~kg} / \mathrm{m}^{2}$ ). Some patients had combined morbidities including hypertension $(50 \%)$, diabetes $(20 \%)$, ischemic heart disease (12\%), and cerebral disease (10\%). Emergency and malignancy related operations were performed in 58 (35\%) and $93(55 \%)$ patients. Most patients (79, $47 \%$ ) had an ASA classification of 2. Lower gastrointestinal and hepatobiliary operations were performed in 64 (38\%) and $58(35 \%)$ patients, respectively.

The median duration of surgery was 207 min (range, 40$645 \mathrm{~min})$. Sixty-four patients $(28 \%)$ received transfusions during the operation and the median blood loss was 300 $\mathrm{mL}$ (range, 100-680 mL). During the operation, 21 patients (13\%) were administered a vasopressor. The median hospital and ICU stays were 19 days (range, 1-72 days) and 2 days (range, 1-27 days). Most patients (121, 72\%) were admitted to the ICU for simple monitoring after surgery; cardiovascular (22\%) and respiratory events $(2 \%)$ were the 
Table 1. Clinical characteristics of patients in intensive care unit after abdominal surgery $(n=168)$

\begin{tabular}{|c|c|}
\hline Variable & \\
\hline Sex, male & $94(56 \%)$ \\
\hline Age, yr & $72(18-909)$ \\
\hline Body mass index, $\mathrm{kg} / \mathrm{m}^{2}$ & $23(15.6-32.9)$ \\
\hline \multicolumn{2}{|l|}{ Comorbidity } \\
\hline Hypertension & $84(50 \%)$ \\
\hline Diabetes & $33(20 \%)$ \\
\hline Ischemic heart disease & $20(12 \%)$ \\
\hline Cerebral disease & $16(10 \%)$ \\
\hline Chronic renal disease & $5(3 \%)$ \\
\hline Chronic liver disease & $3(2 \%)$ \\
\hline Smoking & $35(21 \%)$ \\
\hline \multicolumn{2}{|l|}{ Location of operation } \\
\hline Lower gastro-intestine & $64(38 \%)$ \\
\hline Hepato-biliary organ & $58(35 \%)$ \\
\hline Upper gastro-intestine & $32(19 \%)$ \\
\hline Combined & $14(8 \%)$ \\
\hline Emergency operation & $59(35 \%)$ \\
\hline Laparoscopic operation & $21(13 \%)$ \\
\hline Malignancy related operation & $93(55 \%)$ \\
\hline Duration of operation, min & $207(40-645)$ \\
\hline Blood loss during operation, mL & $300(0-5200)$ \\
\hline Transfusion during operation & $64(38 \%)$ \\
\hline Vasopressor during operation & $21(13 \%)$ \\
\hline \multicolumn{2}{|l|}{ Cause for ICU admission after surgery } \\
\hline Monitoring & $121(72 \%)$ \\
\hline Cardiovascular event & 36 (22\%) \\
\hline Respiratory event & $3(2 \%)$ \\
\hline Others & $7(4 \%)$ \\
\hline Use of mechanical ventilation on admission to ICU & $23(14 \%)$ \\
\hline SAPS II at admission to the ICU & $21(3-71)$ \\
\hline SOFA at admission to the ICU & $2(0-15)$ \\
\hline Hospital stay, d & $19(1-72)$ \\
\hline ICU stay, d & $2(1-27)$ \\
\hline Mortality & $15(9 \%)$ \\
\hline
\end{tabular}

Data are presented as the median (range) or number (\%). ICU: intensive care unit; SAPS II: simplified acute physiology score; SOFA: sepsis related organ failure assessment.

next most common reasons for admission to the ICU. The median SAPS II and SOFA scores upon admission to the ICU were 21 (range, 3-71) and 2 (range, 0-15). ICU mortality was $9 \%$ (15 patients). Seven patients died of sepsis and three of pneumonia. Other causes of death were cerebral hemorrhage, gastric ulcer bleeding, cancer aggravation, and ischemic colitis. One patient died of cardiac arrest due to an unknown cause.

\section{2) Prognostic factors of ICU patients after abdominal surgery}

In univariate analysis, two preoperative factors (BMI $<18.5 \mathrm{~kg} / \mathrm{m}^{2}[\mathrm{p}<0.001]$ and a serum albumin $<3.0 \mathrm{~g} / \mathrm{dL}$ $[p=0.0092])$, two operative factors including the need for transfusion $(p=0.008)$ and vasopressor $(p=0.013)$ during surgery), and three postoperative variables (acute respiratory failure requiring mechanical ventilation immediately following surgery [p $<0.001]$, SOFA score $[p=0.001]$ and SAPS II score $[\mathrm{p}=0.001]$ ) were associated with mortality. However old age, comorbid disease, cancer related operations, emergency operations, and longer operation times were not associated with mortality of patients admitted to the ICU after abdominal surgery (Table 2).

The Cox regression hazard model adjust for age, sex, and SAPS II, revealed that a BMI $<18.5 \mathrm{~kg} / \mathrm{m}^{2}(\mathrm{p}<0.001$, HR $8.690,95 \%$ CI $2.990-25.258$ ) and mechanical ventilation after surgery ( $\mathrm{p}<0.001$, HR 34.671, 95\% CI 6.440-186.649) were independent predictive factors for mortality. The Kaplan-Meier survival curve showed that patients with a lower BMI and who required mechanical ventilation displayed higher mortality (Table 3 and Fig. 1).

\section{Discussion}

The data revealed that low BMI and postsurgical mechanical ventilation are associated with ICU mortality and poor prognosis of abdominal surgery patients.

Mortality of patients admitted to the ICU remains high, and the estimated mean overall ICU mortality in some studies is approximately $15 \% \cdot[11]$ In the present study, the ICU mortality of patients after abdominal surgery was $9 \%$, higher than that of patients in the surgical ICU in other studies $(2.4 \%-7.6 \%),[12,13]$ these values are however lower than the overall mortality in the general ICU or medical ICU. $[11,14,15]$ Studies of post surgical complication and mortality have shown higher mortality rates for patients after thoracic and abdominal surgery or patients with other forms of 
Table 2. Univariate analysis of factors related to mortality of patients in the intensive care unit after abdominal surgery $(n=168)$

\begin{tabular}{|c|c|c|c|}
\hline Variable & Hazard ratio & $95 \% \mathrm{Cl}$ & $p$ value \\
\hline \multicolumn{4}{|l|}{ Preoperative factors } \\
\hline Sex, male & 1.602 & $0.548-4.688$ & 0.389 \\
\hline Age & 0.086 & $0.944-1.097$ & 0.086 \\
\hline Body mass index $\leq 18.5 \mathrm{~kg} / \mathrm{m}^{2}$ & 8.651 & $3.131-23.906$ & $<0.0001$ \\
\hline \multicolumn{4}{|l|}{ Comorbidities } \\
\hline Hypertension & 1.961 & $0.657-5.852$ & 0.227 \\
\hline Diabetes & 0.936 & $0.261-3.355$ & 0.919 \\
\hline Ischemic heart disease & 1.856 & $0.243-14.190$ & 0.551 \\
\hline Smoking & 0.471 & $0.171-1.298$ & 0.145 \\
\hline ASA classification $\geq 3$ & 1.502 & $0.535-4.221$ & 0.440 \\
\hline Creatinine $\geq 1$ mg/dL & 1.759 & $0.638-4.850$ & 0.275 \\
\hline Albumin $<3 \mathrm{~g} / \mathrm{dL}$ & 3.999 & $1.273-12.562$ & 0.018 \\
\hline \multicolumn{4}{|l|}{ Operative factors } \\
\hline Region of operation, lower gastrointestine & 1.432 & $0.519-3.949$ & 0.488 \\
\hline Cancer-related operation & 0.449 & 0.143-1.409 & 0.170 \\
\hline Laparoscopic operation & 0.040 & $0-29.5$ & 0.340 \\
\hline Emergency operation & 2.130 & $0.772-5.874$ & 0.144 \\
\hline Duration of operation $>4 \mathrm{hr}$ & 1.463 & $0.500-4.279$ & 0.488 \\
\hline Transfusion during operation & 4.705 & $1.498-14.781$ & 0.008 \\
\hline Vasopressor during operation & 3.899 & $1.330-11.425$ & 0.013 \\
\hline \multicolumn{4}{|l|}{ Postoperative factors } \\
\hline Use of mechanical ventilation on admission to ICU & 51.487 & $11.547-229.579$ & $<0.0001$ \\
\hline ICU stay & 1.085 & $0.306-3.844$ & 0.900 \\
\hline SAPS $\|$ at admission to ICU & 1.091 & $1.055-1.128$ & 0.001 \\
\hline SOFA at admission to ICU & 1.322 & $1.171-1.492$ & 0.001 \\
\hline
\end{tabular}

Data are presented as the median (range) or number (\%). ICU: intensive care unit; SAPS II: simplified acute physiology score; SOFA: sepsis related organ failure assessment.

Table 3. Adjusted predictors related to mortality of patients in the intensive care unit after abdominal surgery

\begin{tabular}{|c|c|c|c|}
\hline Variable & Hazard ratio & $95 \% \mathrm{Cl}$ & $\mathrm{p}$ value \\
\hline \multicolumn{4}{|l|}{ Preoperative factors } \\
\hline Body mass index $\leq 18.5 \mathrm{~kg} / \mathrm{m}^{2}$ & 8.690 & $2.990-25.258$ & $<0.001$ \\
\hline Albumin $<3 \mathrm{~g} / \mathrm{dL}$ & 1.907 & $0.540-6.732$ & 0.316 \\
\hline \multicolumn{4}{|l|}{ Operative factors } \\
\hline Transfusion during operation & 3.348 & $0.993-11.288$ & 0.051 \\
\hline Vasopressor during operation & 1.696 & $0.385-7.475$ & 0.485 \\
\hline \multicolumn{4}{|l|}{ Postoperative factors } \\
\hline Use of mechanical ventilation on admission to ICU & 34.671 & $6.440-186.649$ & $<0.001$ \\
\hline
\end{tabular}

Predictors were adjusted by age, sex, and SAPS II. Data are presented as the median (range) or number (\%). Cl: confidence interval; ICU: intensive care unit.

surgery.[1,12] Mortality rates in our study were higher than mortality rates in other studies of the surgical ICU because our study only analyzed data on abdominal surgery, exclud- ing other surgeries. The discrepancy between the mortality of patients in the ICU after abdominal surgery and that in the medical or overall ICU results from admission to the 

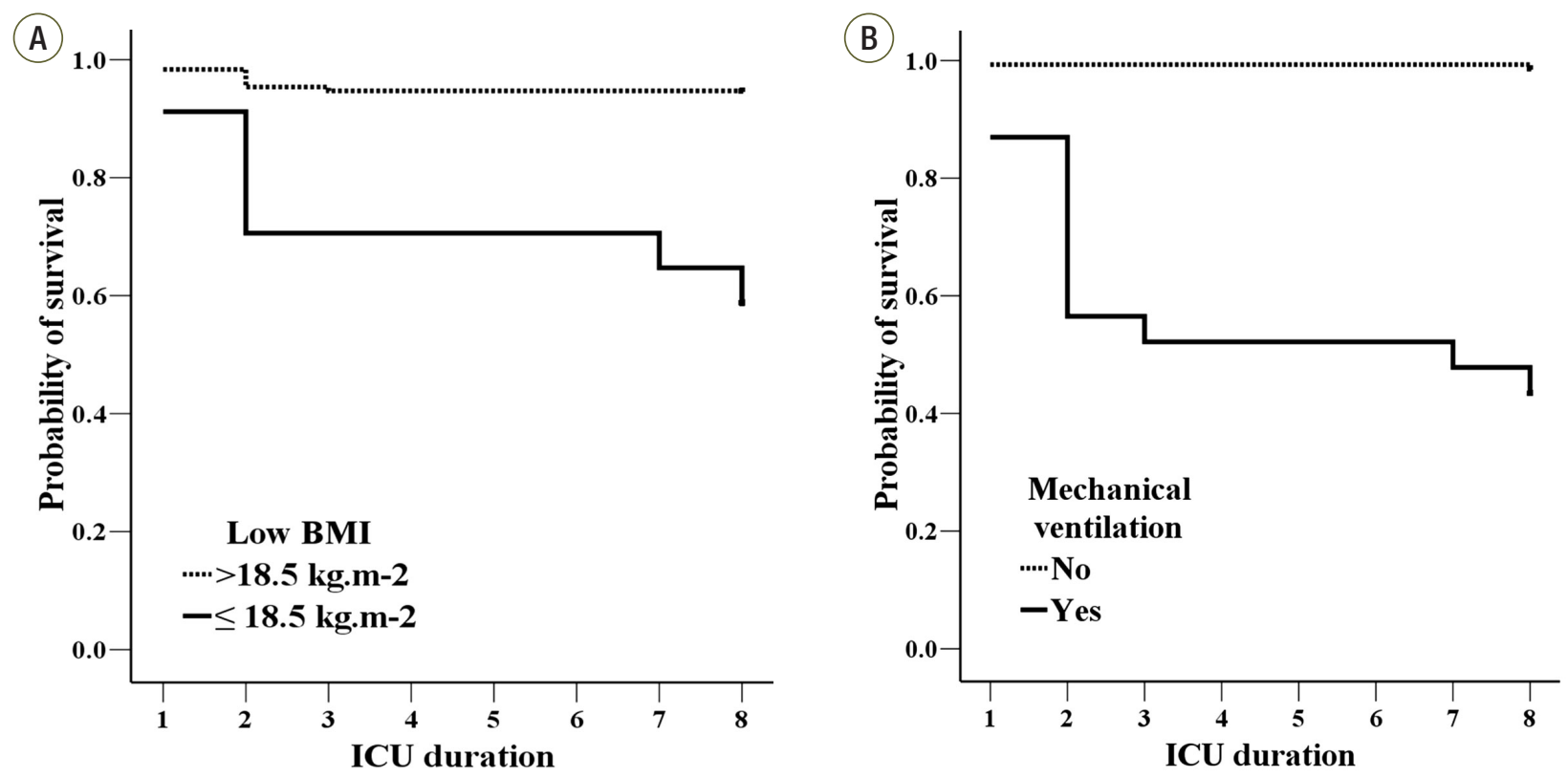

Fig. 1. Survival curve according to BMI and mechanical ventilation for 168 patients admitted to the surgical intensive care unit after abdominal surgery. BMI: body mass index; ICU: intensive care unit.

ICU after surgery for simple monitoring. This study showed that all 21 post-laparoscopy ICU patients who underwent relatively minor abdominal surgery survived. These patients were admitted to the ICU for simple postoperative monitoring due to old age, comorbid conditions or other reasons. ICU settings are expensive and have limited resources, and ICU patients suffer from unfamiliar circumstances and excessive procedures.[1-4] Thus, the decision to admit a patient to the ICU after abdominal surgery should be undertaken cautiously, taking into consideration the effective use of limited resources and the comfort of patients.

In our study, a low BMI was associated with higher mortality of ICU patients after abdominal surgery. Obesity of patients was risk factors for postoperative complications after heart,[16] uro-system,[17] and gynecologic[18] surgeries. However, other studies have found that BMI is not significantly correlated with severe postoperative morbidity or mortality with the exception of minor postoperative complications such as wound infection.[19-21] In patients with intra-abdominal cancer surgery, obesity was not elevated risk for postoperative complication and mortality, however, lower weight patients have increased risk of postoperative mortality about five fold.[9] Excessive subcutaneous fat and oxygen demands of tissue with relatively low blood flow and insufficient antibiotic levels in the tissues of obese patients result in increased risk of wound infection.[22] Whereas obese patients have adequate nutritional reserves, patients with a low BMI are in an insufficient nutritional state, and are relatively unprepared for the hyper-metabolic state and oxidative stress that occur after surgery.[9] In particular, abdominal surgery requires a longer fasting period than other operations. These factors seem to result in the high mortality of patients with a low BMI in the ICU after abdominal surgery.

In studies of BMI and mortality in Asian and Korean,[23-25] underweight and overweight person had higher rates of death than person of normal weight. The association of BMI with death varied according to the cause of death and was affected by age, sex, and smoking history.[23] Low BMI can be an indicator of certain other chronic medical conditions or of poor health or a low standard of living, which may contribute to such conditions as undernutrition and may increase the risk of premature death.[24] A trend of graded inverse association between BMI and hospital mortality was found in critically ill patients in Korean cohort study.[25] Although BMI did not have a significant influence on ICU mortality in Korean study,[26] BMI at ICU admission was a determinant of survival of 30 days and 12 months in other study.[27] Obesity was not associated with adverse outcomes.[27] These studies suggested that obesity 
in contrast to low BMI provides a nutritional reserve that, in times of stress and increased metabolic demand, helps to prevent the long-term complications associated with critical illness. In our study, the longer fasting time associated with abdominal surgery might have resulted in the association between prognosis and low BMI.

The postoperative use of a mechanical ventilator was associated with a poor outcome. This appears to be due to respiration failure after the operation, indicating hemodynamic, respiratory, and consciousness compromise. Postsurgical mechanical ventilation due to respiratory failure and pulmonary complications result in increasing hospital stays, morbidity, and mortality.[28] Thus, non-invasive ventilation may be considered a prophylactic and therapeutic tool for improving gas exchange in postoperative patients.[28] Insufficient deep breathing or sputum expectoration due to pain and diaphragm dysfunction leads to increased pulmonary complications after abdominal surgery, particularly for upper abdominal surgery including the stomach or hepato-biliary tract, which are closer to the diaphragm.[6] However, we did not find differences in the use of mechanical ventilation between upper-abdominal surgery and that at other sites in this study.

This study has a number of limitations. The most important is the small number of subjects. Second, we selected subjects retrospectively in a single medical center. However, a significant correlation was found between low BMI and mortality using a Cox proportional hazards model. Future, large, prospective cohort studies should be performed.

In conclusion, patients with a poor prognosis should be stratified to ensure effective use of the ICU. If patients have minor risk factor including old age, comorbid conditions or other reasons, physicians should cautiously decide whether ICU admission is necessary for simple postoperative monitoring. In patients ICU admission immediately after abdominal surgery, it should be considerable as important predictors which were low BMI and postsurgical mechanical ventilation.

\section{ORCID}

Yun Su Sim

Jin Hwa Lee

Yon Ju Ryu http://orcid.org/0000-0002-3746-4947 http://orcid.org/0000-0003-0843-9862 http://orcid.org/0000-0003-4059-9401

\section{References}

1) Sirio CA, Martich GD: Who goes to the ICU postoperatively? Chest 1999; 115: 125S-9S.

2) Bastounis E, Filis K, Georgopoulos S, Bakoyannis C, Xeromeritis N, Papalambros E: Selective use of the intensive care unit after elective infrarenal abdominal aortic aneurysm repair. Int Angiol 2003; 22: 308-16.

3) Bertges DJ, Rhee RY, Muluk SC, Trachtenberg JD, Steed DL, Webster MW, et al: Is routine use of the intensive care unit after elective infrarenal abdominal aortic aneurysm repair necessary? J Vasc Surg 2000; 32: $634-42$.

4) To EW, Tsang WM, Lai EC, Chu MC: Retrospective study on the need of intensive care unit admission after major head and neck surgery. ANZ J Surg 2002; 72: 11-4.

5) Atalay F, Uygur F, Cömert M, Özkoçak I: Postoperative complications after abdominal surgery in patients with chronic obstructive pulmonary disease. Turk J Gastroenterol 2011; 22: 523-8.

6) Bapoje SR, Whitaker JF, Schulz T, Chu ES, Albert RK: Preoperative evaluation of the patient with pulmonary disease. Chest 2007; 132: 1637-45.

7) Kroenke K, Lawrence VA, Theroux JF, Tuley MR, Hilsenbeck S: Postoperative complications after thoracic and major abdominal surgery in patients with and without obstructive lung disease. Chest 1993; 104: 1445-51.

8) Massarweh NN, Legner VJ, Symons RG, McCormick WC, Flum DR: Impact of advancing age on abdominal surgical outcomes. Arch Surg 2009; 144: 1108-14.

9) Mullen JT, Davenport DL, Hutter MM, Hosokawa PW, Henderson WG, Khuri SF, et al: Impact of body mass index on perioperative outcomes in patients undergoing major intra-abdominal cancer surgery. Ann Surg Oncol 2008; 15: 2164-72.

10) WHO Expert Consultation: Appropriate body-mass index for Asian populations and its implications for policy and intervention strategies. Lancet 2004: 363: 157-63.

11) Azoulay E, Adrie C, De Lassence A, Pochard F, Moreau D, Thiery G, et al: Determinants of postintensive care unit mortality: a prospective multicenter study. Crit Care Med 2003; 31: 428-32. 
12) Rhodes A, Moreno RP, Metnitz B, Hochrieser H, Bauer P, Metnitz P: Epidemiology and outcome following post-surgical admission to critical care. Intensive Care Med 2011; 37: 1466-72.

13) Cavaliere F, Conti G, Costa R, Masieri S, Antonelli M, Proietti R: Intensive care after elective surgery: a survey on 30-day postoperative mortality and morbidity. Minerva Anestesiol 2008; 74: 459-68.

14) Haidri FR, Rizvi N, Motiani B: Role of APACHE score in predicting mortality in chest ICU. J Pak Med Assoc 2011; 61: 589-92.

15) Eng PC, Chng HH, Feng PH: Mortality patterns in a medical intensive care unit. Singapore Med J 1992; 33: 24-6.

16) Fasol R, Schindler M, Schumacher B, Schlaudraff K, Hannes W, Seitelberger R, et al: The influence of obesity on perioperative morbidity: retrospective study of 502 aortocoronary bypass operations. Thorac Cardiovasc Surg 1992; 40: 126-9.

17) Lee CT, Dunn RL, Chen BT, Joshi DP, Sheffield J, Montie JE: Impact of body mass index on radical cystectomy. J Urol 2004; 172: 1281-5.

18) Prem KA, Mensheha NM, McKelvey JL: Operative treatment of adenocarcinoma of the endometrium in obese women. Am J Obstet Gynecol 1965; 92: 16-21.

19) Dindo D, Muller MK, Weber M, Clavien PA: Obesity in general elective surgery. Lancet 2003; 361: 2032-5.

20) Klasen J: The effect of intravenous lidocaine on somatosensory evoked potentials during scoliosis surgery.
Anesth Analg 1997; 85: 228.

21) Thomas EJ, Goldman L, Mangione CM, Marcantonio ER, Cook EF, Ludwig L, et al: Body mass index as a correlate of postoperative complications and resource utilization. Am J Med 1997; 102: 277-83.

22) Pai MP, Bearden DT: Antimicrobial dosing considerations in obese adult patients. Pharmacotherapy 2007; 27: 1081-91.

23) Jee SH, Sull JW, Park J, Lee SY, Ohrr H, Guallar E, et al: Body-mass index and mortality in Korean men and women. N Engl J Med 2006; 355: 779-87.

24) Zheng W, McLerran DF, Rolland B, Zhang X, Inoue M, Matsuo K, et al: Association between body-mass index and risk of death in more than 1 million Asians. N Engl J Med 2011; 364: 719-29.

25) Lim SY, Choi WI, Jeon K, Guallar E, Koh Y, Lim CM, et al: Body mass index and mortality in Korean intensive care units: a prospective multicenter cohort study. PLoS One 2014; 9: e90039.

26) Lim SY, Kim SI, Ryu YJ, Lee JH, Chun EM, Chang JH: The body mass index as a prognostic factor of critical care. Korean J Intern Med 2010; 25: 162-7.

27) Peake SL, Moran JL, Ghelani DR, Lloyd AJ, Walker MJ: The effect of obesity on 12-month survival following admission to intensive care: a prospective study. Crit Care Med 2006; 34: 2929-39.

28) Chiumello D, Chevallard G, Gregoretti C: Non-invasive ventilation in postoperative patients: a systematic review. Intensive Care Med 2011; 37: 918-29. 